\title{
Artigos
}

\section{A aprendizagem de línguas estrangeiras conferindo identidades a um sujeito}

\author{
Juliana Harumi Chinatti*
}

Resumo: Este estudo visa abordar as relações entre identidades, crenças e ensino-aprendizagem de língua estrangeira. Para tanto, apresenta investigação sobre as identidades e crenças conferidas pela aprendizagem de língua inglesa e espanhola de uma estudante da rede pública de ensino do Distrito Federal. Os resultados mostram como o sujeito de pesquisa esforça-se em construir sua identidade social vinculada à língua inglesa, apesar da falta de credibilidade do ensino de línguas na escola pública regular.

Palavras-chave: crenças; identidades; aprendizagem de línguas.

Resumen: El objetivo de este estudio es abordar las relaciones entre identidades, creencias, enseñanza y aprendizaje de lenguas extranjeras. Se presenta una investigación sobre las identidades y creencias conferidas por el aprendizaje de lengua inglesa y española de una estudiante de escuela pública del Distrito Federal. Los resultados muestran cómo el sujeto de la investigación se esfuerza en construir su identidad social vinculada al idioma inglés, a pesar de la falta de credibilidad de la enseñanza de idiomas en la escuela pública regular.

Palabras clave: creencias; identidades; aprendizaje de lenguas.

Este estudo nasceu do interesse em investigar as questões relativas às crenças, às identidades e ao ensino-aprendizagem de línguas estrangeiras no contexto da rede pública de ensino no Distrito Federal, após o estabelecimento do espanhol como disciplina de oferta obrigatória e de matrícula optativa para os alunos de ensino médio das escolas do Brasil, desde o ano de 2010 (BRASIL, 2005).

O foco da análise está em tentar perceber como uma estudante secundarista constrói sua compreensão a respeito da aprendizagem da língua espanhola (doravante LE) e da língua inglesa (a partir de agora LI) considerando o contexto e o processo de

\footnotetext{
* Mestranda no Programa de Pós-Graduação em Linguística Aplicada da UnB, sob orientação do Prof. Dr. Kleber Aparecido da Silva.
} 
ensino-aprendizagem no desafio de adquirir novas formas linguísticas de comunicação, de relação e inserção no mundo.

O processo de ensino-aprendizagem de línguas implica em transformações e conflitos de ordem subjetiva. No caso relatado, veremos como a estudante de línguas se posiciona e atribui direitos e responsabilidades dentro desse processo de maneiras distintas com relação à LI e à LE. Além disso, a partir das crenças e identidades assumidas pela participante da pesquisa, buscaremos ver como e por que, provavelmente, valores diversos estão em jogo na aprendizagem.

Esta investigação parte do pressuposto de que crenças e identidades, constituídas por meio da interação social, possíveis pela e na linguagem, podem ser usadas para ampliar o entendimento do processo de ensinar e aprender línguas no contexto da escola pública.

Feita essa consideração, pretendemos contribuir com uma pequena reflexão sobre as questões concernentes ao campo das Práticas e Teorias no EnsinoAprendizagem de Línguas com enfoque nos Processos Formativos de Professores e Aprendizes de Línguas, para isso, levantamos às seguintes questões:

1. Como a aprendizagem de línguas constrói sua significação sobre o processo de ensino-aprendizagem das línguas inglesa e espanhola na escola pública?

2. Como se apresentam as crenças e identidades a partir dos papéis e valores subjacentes atribuídos às aprendizagens?

Para amparar nossas reflexões neste artigo, servimo-nos de leituras que abrangem os temas de linguagem (AUSTIN, 1990), crenças sobre processo de ensinoaprendizagem de línguas (BARCELOS \& VIEIRA-ABRAHÃO, 2006; SILVA \& ROCHA, 2007) e identidades (PEIRCE, 1995; SILVA, 2000).

\section{Perspectivas teóricas}

Antes de tratarmos propriamente das Crenças sobre o Ensino e a Aprendizagem de Línguas (doravante CEAL) e as identidades conferidas-assumidas, faz-se necessário demarcar nossa interpretação sobre o papel relevante que a linguagem desempenha nos diversos processos de socialização dos indivíduos e, especialmente, nos contextos em que se pensa ou se questionam as identidades e o processo de ensino-aprendizagem, tanto em sala como fora dela. Sendo assim, nesta parte do trabalho, oferecemos as 
perspectivas teóricas pelas quais se fundaram a investigação. Para melhor compreensão do estudo, a dividimos em quatro seções, que versam, em sequência, sobre: a questão da Linguagem nas relações sociais e na construção da nossa compreensão do mundo, a Abordagem como força potencial orientadora,das CEAL e, por último, das Identidades em jogo.

\section{A construção do Mundo pela e na linguagem}

Diz o Evangelho de João (1:1-14): "No princípio era o Verbo (...). Tudo foi feito por ele, e sem ele nada foi feito. Nele havia a vida, e a vida era a luz dos homens. (...) E o Verbo se fez carne e habitou entre nós".

Os estudos estruturalistas da linguagem tiveram grande repercussão sobre o pensamento filosófico e científico, no século XIX em diante, constituindo-se como método de análise, que consiste em reunir modelos explicativos da realidade, que são as estruturas.

Em seus estudos sobre a língua, Ferdinand de Saussure (1969), referência na abordagem estrutural, postulou a existência de quatro dicotomias para os estudos da linguagem: diacronia x sincronia; significante $\mathrm{x}$ significado; paradigma $\mathrm{x}$ sintagma, $\mathrm{e}$ língua $\mathrm{x}$ fala. Nesta última dicotomia, língua $\mathrm{x}$ fala, os estudos da Linguística deram destaque às formas da língua em "detrimento das substâncias do corpo e da voz: i langue est une forme et non une substance" (SAUSSURE, 1995 apud PEZANI FILHO, 2007, p. 106), ou seja, para essa filosofia tradicional, a abordagem de compreensão da linguagem era por meio da descrição das formas estruturais.

Benveniste (1902-1976), que tinha a semântica como centro de suas discussões, afirma que a percepção da linguagem como instrumento deve encher-nos de desconfiança e que tentar fazer essa diferença instrumental é tentar opor homem e natureza, como se fosse possível chegar à projeção do homem anterior à fala. "É um homem falando que encontramos no mundo, um homem falando com outro homem, e a linguagem ensina a própria definição do homem" (1958, p. 248).

Por muito tempo, os campos das ciências humanas e sociais permaneceram estruturados a partir de pressupostos que concebiam a língua(gem) como instrumento de mera troca de informação, a qual era destinada a relatar algo pré-existente no mundo, ou seja, a língua(gem) se prestava à descrição de fatos, que poderiam ser considerados 
verdadeiros ou falsos. Adotava-se uma postura de isomorfismo entre a estrutura da linguagem e a estrutura do mundo, onde aquela era tida como recurso neutro tanto do fazer científico como da vivência cotidiana, pois havia um espelhamento do mundo pela linguagem. Dessa forma, os saberes estavam impregnados por uma linguagem tida como formal e meramente representacionalista.

Em oposição a esse movimento, no interior da Filosofia da Linguagem, surge a Teoria dos Atos de Fala, postulada pelo filósofo inglês da escola de Oxford, John Langshaw Austin (1911-1960), que teve, em 1962, livro publicado sob o título How to do things with words. Como bem explica o título da obra póstuma, para além de uma abordagem instrumental da linguagem, onde é possível descrever o estado das coisas, segundo Austin, as palavras possuem poder de ação e criação, como já narrado pelas histórias bíblicas da criação do mundo pela Palavra - Disse Deus: haja luz (Gênesis 1:3). Dessa forma, é introduzido o conceito performativo (AUSTIN, 1990). Austin nomeia de performatividade o poder de criação dos atos de fala, asseverando que o performativo é o próprio ato de realização da fala-ação (OTTONI, 2002, p. 129).

$\mathrm{Na}$ análise do diálogo, há que se ponderar também as condições necessárias para que a realização do enunciado performativo aconteça e as posições ocupadas pelos sujeitos falantes. A essas condições de realização, Austin chamou condições de felicidade .

Nesse sentido, saímos de uma concepção de língua(gem) apenas como instrumentos de comunicação em direção de uma concepção de estrutura estruturante do conhecimento e da realidade.

Partimos de pressupostos que percebem a linguagem não apenas por seu aspecto utilitário-instrumental, mas também como estruturante da realidade que nos rodeia. Os discursos são, então, sequência de signos que produzem significados e materialidades. Admitimos que a realidade seja formada por natureza simbólica e que há na linguagem força construcionista dessa realidade, influenciando na fixação de identidades e na formação CEAL.

\section{A abordagem como potencial força orientadora}

Partilhamos da ideia de que a abordagem é "o termo mais abrangente [que método] a englobar os pressupostos teóricos acerca da língua e da aprendizagem" 
(LEFFA, 1998, p. 211-212), mas não apenas pressupostos teóricos constituem a abordagem (de ensinar ou aprender) também crenças e identidades.

Para Almeida Filho (2002, p. 3), a abordagem é:

Filosofia de trabalho, um conjunto de pressupostos explicitados, princípios estabilizados ou mesmo crenças intuitivas quanto à natureza da linguagem humana, de uma língua estrangeira em particular, de aprender e de ensinar línguas, da sala de aula de línguas e de papéis de aluno e do professor de outra língua.

Para nós, a abordagem configura-se como força do pensamento e da linguagem composta por pressupostos teóricos, crenças, identidades, que se conformam potencial orientador da compreensão do processo de ensinar-aprender e das práticas, técnicas e procedimentos de ação ou cognição dirigidos à aprendizagem.

Dessa forma, dois construtos específicos que compõem as abordagens de aprender nos interessam nesta investigação: as crenças e as identidades.

\section{As Crenças na aprendizagem de línguas}

A noção de crenças é introduzida por Hosenfeld em 1978 como "mini-teorias de aprendizagem de línguas de alunos", que influenciam o processo de ensinoaprendizagem de línguas. O termo utilizado por este pesquisador associa as concepções dos aprendizes à ciência, ainda que de forma subestimada.

Os estudos em CEAL começaram no exterior nos anos 1970-80 e em dez anos chegaram ao Brasil. Á época, estavam marcados por uma abordagem normativa de investigação (termo utilizado por Holliday em 1994), segundo Barcelos (2001, p. 76). Acreditava-se que as crenças eram estruturas mentais, estáveis, fixas e localizadas dentro da mente das pessoas e distintas do conhecimento (BARCELOS \& VIEIRAABRAHÃO, 2006 p. 18). Além disso, as crenças eram categorizadas como boas e ruins, e seriam preditivas de comportamentos que constituiriam bons e maus alunos.

Para Barcelos, outra perspectiva epistemológica e metodológica dentro dos estudos de crenças seria a abordagem metacognitiva, que compreende crenças dentro da noção de conhecimento cognitivo, definido por Weden como “estável, declarável, embora às vezes incorreto, que os aprendizes têm sobre a linguagem, a aprendizagem e a aprendizagem de línguas" (apud BARCELOS, 2001, p. 79). Nesse sentido, a definição 
apresentada por esta abordagem assemelha-se à anterior, na qual as crenças eram vistas como obstáculo à aprendizagem (BARCELOS, 2001, p. 80).

A perspectiva adotada aqui para o estudo ressalta o caráter discursivo das crenças. Dessa forma, as explicações em torno dos aspectos da aprendizagem são vistas como falas construídas socialmente e não apenas como produtos originários individualmente na mente (ASSIS-PATERSON et al., 2010 p. 199). Tal qual propõem Barcelos e Kalaja (2003 apud BARCELOS \& VIEIRA-ABRAHÃO, 2006, p.18), compreendemos crenças como: (a) Dinâmicas; (b) Emergentes, socialmente construídas e situadas contextualmente; (c) Experienciais; (d) Mediadas; (e) Paradoxais e contraditórias; e, (f) Não tão facilmente distintas do conhecimento.

Como concepções norteadoras, localizadas em tempo e espaço sócio-históricos, constituídas na e pela linguagem, as crenças são necessariamente dialógicas, ou seja, só são possíveis pela presença de outras vozes; o objeto de qualquer discurso, seja sobre CEAL ou mesmo identidade, "já foi falado, esclarecido e julgado de diversas maneiras, é o lugar onde se cruzam, se encontram e se separam diferentes pontos de vista, visões de mundo, tendências" (BAKHTIN, 2000, p. 319). Somando-se a essa visão, compartilhamos com Silva e Rocha (2007, p. 1021) quando "inferem um estreito vínculo entre o conceito de crenças e a perspectiva ideológica, inerente à linguagem e à educação".

Com base em estudos sobre a filosofia da linguagem (AUSTIN, 1990; BAKHTIN, 2000), partilhamos da ideia de Kramsch (2003, apud BARCELOS \& VIEIRA-ABRAHÃO, 2006, p.18) para o qual "as crenças não só representam uma realidade social, mas também constroem essa realidade".

No tocante às investigações preocupadas com a educação e a aprendizagem, e mais especificamente aprendizagem de línguas, o estudo de crenças é essencial para uma reflexão sobre: (a) as abordagens envolvidas no processo de ensinar e aprender; (b) as escolhas, as técnicas, os procedimentos e as estratégias de ensino e de aprendizagem empregados; (c) a reflexão e mudança das práticas; (d) as identidades e diferenças que se constituem no processo de ensino-aprendizagem de línguas, e (e) as dimensões éticas e políticas que perpassam o ensino e a aprendizagem de línguas.

Diante do exposto, reiteramos como linguagem e crenças estão intrinsecamente relacionadas, o que nos auxiliará a relacioná-las às problemáticas das identidades em jogo. 


\section{Loquor, ergo sum - A aprendizagem de línguas e as identidades em jogo}

Le Page (2009, p. 974) afirma que

Speech acts are acts of projection: the speaker projects his inner universe via a common language (with its nuances of grammar and, vocabulary, and accent) or via particular choice of language where choices exist (in multilingual settings).

Se considerarmos que todo ato de fala é um ato de identidade, de acordo com Le Page, sendo que a linguagem é o índice por excelência da identidade (1980), a proposição cartesiana penso, logo existo poderia ser melhor bem adaptada, no nosso contexto de aprendizagem de línguas, para falo, logo existo. Mas será que esse princípio que entende o homem como "um ser pensante, consciente, centro do conhecimento, dotado de uma identidade autônoma" (ECKERT-HOFF, 2008, p. 36, apud ORRÚ, 2010) realmente confere visibilidade, acesso e existência, muitas vezes prometidos pelo exercício de falar uma língua estrangeira, a todas as mulheres e homens que reivindicam ou são convocados pelas identidades em jogo?

Sabe-se que não se pode falar em hierarquias linguísticas entre uma ou outra língua, mas que, se as línguas cumprem, do ponto de vista do uso, com suas funções de comunicação, todas elas são bem sucedidas per si. Entretanto, as línguas não podem ser consideradas como estruturas autônomas e independentes. Como exemplo da dependência das línguas às mulheres e homens que as falam - e que são falados por elas, citamos os processos de glotofagia (desaparecimento total de uma língua) ou de hegemonia linguística que são postos para se verificar como fatores extralinguísticos, dentre eles a resistência ou investimentos de seus falantes, também devem ser considerados para as existências e predominâncias das línguas. Logo, podemos dizer que a hierarquia entre os usos variados da língua ou entre as línguas são produzidas e marcam também os sujeitos que as falam.

De acordo com Pierce (1995), ao falarmos outra língua, nos comportamos de forma particular em vários aspectos, entramos em contato com diferentes formas de ver, de ouvir, de expressar-se e de investir no mundo.

A construção da identidade social que, segundo Peirce (1995), são as várias formas pelas quais as pessoas se veem em relação aos outros, e como elas enxergam seus passados e seus futuros, neste estudo, está intimamente ligada ao falar uma língua 
estrangeira com a promessa de poder acessar recursos materiais e simbólicos diversos que se pretendem disponíveis para os aprendizes que os busquem.

Para a compreensão da produção social das identidades como signos que são, lançamos mão dos estudos da linguística estrutural para nos servir de metáfora. Segundo Saussure, a língua é um sistema composto por elementos, no qual cada um deles só se define em oposição a outro elemento revelando, por meio da diferenciação, seu valor. Como exemplo, temos que as mudanças dos fonemas iniciais das palavras, ilustradas a seguir, são suficientes para estabelecer uma gama identidades-diferenças: /mala/,/pala/, /cala/, /sala/, /vala/, /tala/. Para Saussure, na língua só existem diferenças. Logo, o signo carrega em si tanto o que é como o que não é.

Silva (2000) ilustra bem a produção da identidade utilizando-se das representações de nacionalidades. Falar de identidade afirmada positivamente, por exemplo: "eu sou brasileira", é, ao mesmo tempo, falar de maneira oculta em uma gama de diferenças afirmadas negativamente: "não sou japonesa", "não sou árabe", "não sou americana". Dessa forma, só é possível fazer a afirmação "sou brasileira" "porque há outros seres humanos que não são brasileiros" (SILVA, 2000, p. 75).

Ainda em Silva (2000), encontramos contribuições do pensamento pós-moderno de Derrida, o qual volta ao sistema estrutural da língua, conformada por signos, para desenvolver a noção de metafísica da presença. De acordo com Silva (2000, p. 78):

O signo é um sinal, uma marca, um traço que está no lugar de alguma outra coisa, o qual pode ser um objeto concreto (o objeto gato), um conceito ligado a um objeto concreto (o conceito de gato) ou conceito abstrato (amor). O signo não coincide com a coisa ou o conceito.

Assim, com o signo, temos a ilusão da presença da coisa, mas jamais temos a própria coisa, “indefinidamente adiada" (SILVA, 2000, p. 79). A característica do adiamento da presença nos interessa à medida que somos constituídos discursivamente (tanto no que tange às crenças, como às identidades), na e por uma língua(gem), como sistema de significação e de diferença, vacilante. Assim, (SILVA, 2000, p. 80) conclui que a identidade e a diferença, definidas em parte por meio da linguagem, estão marcadas também pela indeterminação e pela instabilidade.

Como visto em seção anterior, a partir da perspectiva de Austin (1990), as palavras realizam muito mais do que apenas referências ou descrições dos estados das 
coisas. Por meio das palavras, podemos realmente fazer com que fatos aconteçam, tratase do poder performativo da linguagem.

Identidade-Diferença, como signos linguísticos, também são criadas a partir da performatividade da língua e só são reconhecidas a partir do momento da repetição e da convenção. Dessa maneira, só são possíveis por meio do exercício da citacionalidade (DERRIDA apud SILVA, 2000, p. 94), ou seja, a característica de repetibilidade dos signos que dão origem o processo de produção de identidades e diferenças. Contudo como seres criativos e resistentes que podemos ser, é possível nos afastarmos do sistema de citacionalidade, que muitas vezes discrimina e violenta, rumo a novos caminhos. Assim, Judith Butler (1999 apud SILVA, 2000, p. 95) compreende que a mesma repetibilidade que garante a eficácia dos atos performativos que reforça identidades existentes pode também significar a possibilidade de interrupção.

Os estudos de identidade e diferença importam para a educação de línguas a partir do momento que são percebidas como relação social assimetricamente estabelecida, submetidas a vetores de força, a relações de poder, que envolvem disputa mais ampla por outros recursos simbólicos e materiais (SILVA, 2000, p. 81).

A seguir, passaremos à explicação da metodologia de pesquisa dirigida nesta investigação, instrumentos utilizados, escolha e descrição da participante de pesquisa bem como de seu contexto de aprendizagem de línguas.

\section{Metodologia da pesquisa}

Esta é uma investigação qualitativa-interpretativista (MOITA LOPES, 1994) que utilizou questionário e entrevista semiestruturados para a coleta dos registros buscando estudar o discurso como constitutivo das experiências de aprendizagem e da vida social. O questionário foi composto por quatro partes, contendo questões fechadas e outras de evocação, com o objetivo de investigar as opiniões, crenças, valores da participante da pesquisa sobre os conceitos de língua, linguagem e motivações para se estudar línguas. A primeira delas visava à coleta de registros sócio-demográficos; a segunda pretendia recolher informações sobre a importância que a participante aferia ao estudo das línguas estrangeiras e à presença dessa disciplina no exame do vestibular; a terceira seção tratava da língua espanhola e a última da língua inglesa. 
O outro instrumento metodológico utilizado nesta investigação foi a entrevista semiestruturada, que tentou reconstruir as experiências vividas com línguas estrangeiras da participante. A escolha desse instrumento partiu do interesse em entabular uma conversa, a partir de um roteiro pré-estabelecido, mais aberta sobre as questões da aprendizagem de línguas na escola pública.

Esclarecemos que, nesta etapa inicial da pesquisa, detivemo-nos na análise das memórias e falas da participante sobre as questões relativas a crenças e identidades no ensino-aprendizagem de línguas.

A participante desta pesquisa se chama Fabíola (nome escolhido ao acaso pela pesquisadora) e é aluna do $2^{\circ}$ ano do ensino médio de uma escola pública de Sobradinho-Distrito Federal. Ela tem 19 anos e gosta muito de conversar, escrever músicas, poesias (já tem mais de 100 trabalhos no total) e estudar inglês. Ela se diz muito interessada em aprender inglês, sempre que lê ou ouve alguma palavra na língua, ela logo procura saber o significado. Assim acontece quando escuta uma música. Antes de gostar apenas da sonoridade, do ritmo da música, ela busca o significado do texto.

Neste ano, Fabíola começou a trabalhar em uma empresa de informática. Apesar de, no início, não gostar muito de computador, ela está gostando do serviço, que aparenta oferecer oportunidade de ganho financeiro compensador.

Sobre o futuro profissional, Fabíola afirma ter como objetivo cursar Psicologia ou Psiquiatria. Esse é um plano que ela pretende concretizar. Em relação ao vestibular, ela acredita que o grau de dificuldade é alto para a aprovação, por isso, no momento, ela preocupa-se com as boas perspectivas que tem sobre o trabalho na empresa de informática.

A experiência de aprender línguas de Fabíola começou com a língua inglesa na $8^{\text {a }}$ série do ensino fundamental da escola pública regular. Além de ter sido exposta ao processo de ensino-aprendizagem de língua inglesa, Fabíola também estudou inglês em um centro de línguas público do Distrito Federal, o que parece influenciar muito suas concepções de ensino de línguas. Há um ano, a aprendiz também começou a estudar espanhol nas aulas do ensino médio.

$\mathrm{Na}$ próxima seção, a partir das perspectivas teóricas já apresentadas, ofereceremos a análise e discussão dos dados coletados. 


\section{Análise dos dados}

Os recortes dos registros que trazemos para a análise são provenientes da entrevista que realizamos com Fabíola.

\section{Por que é importante aprender línguas estrangeiras?}

Primeiramente, foi entregue à participante um questionário para que respondesse a algumas questões que visavam recolher informações sócio-demográficas e também sobre concepções sobre ensino-aprendizagem de línguas (EAL).

Na primeira parte, destacou-se a resposta de Fabíola para a questão 3) Você já estudou alguma língua estrangeira? Se sim, qual? Por quanto tempo? Onde? A aluna diz ter estudado inglês, entre 2 e 3 anos, no centro de idiomas público, mas não coloca sua experiência com a LE. Já na entrevista, afirma ter aula de espanhol há pelo menos 1 ano, ou seja, desde 2010, quando teve início a oferta da língua nas escolas públicas do Distrito Federal. Além da ausência da LE, Fabíola tampouco cita a escola regular como espaço para a aprendizagem de línguas, considerando apenas o centro de idiomas.

Pedia-se que fossem listados 5 motivos que justificassem a importância de se aprender línguas. Em ordem de relevância, Fabíola listou:

Por que é importante aprender línguas?

$1^{\circ}$ ) Pelo prazer de falar e aprender algo que goste e vai servir para mais tarde;

$2^{\circ}$ ) conhecer uma cultura diferente;

$3^{\circ}$ ) ajudar a arrumar um bom emprego;

$4^{\circ}$ ) comunicar-se em lugares desconhecidos;

$\left.5^{\circ}\right)$ adquirir conhecimentos novos.

Desde o primeiro contato com a pesquisa, seja no questionário ou na entrevista, Fabíola afirma o prazer como elemento motivador e preponderante na aprendizagem de línguas. Este elemento nos chamará bastante a atenção para a constituição do "gosto" e sua relação com valores subjacentes e processos de repetição, exposição e afirmação ao qual é submetido. 
Ainda na primeira afirmativa, o prazer, como justificativa para a aprendizagem, segue imediatamente associado à noção de utilidade, que como veremos, nas entrevistas, é outro importante componente na constituição das crenças e identidades da aprendizagem.

Os motivos que se seguem a esse estão relacionados às possibilidades de acesso a recursos simbólicos e materiais que outra língua pode oferecer ao sujeito.

A segunda afirmativa, bem como a quinta, por exemplo, relaciona-se com a possibilidade de ampliação de conhecimentos. Já a terceira expõe o potencial da língua como elemento que auxilia no alcance de um trabalho. Por fim, a quarta assertiva revela o caráter comunicativo da aprendizagem de uma língua, qualificada como chave de acesso a lugares outros que não os relativos à língua materna (LM).

Os pontos aqui listados serão retomados e ampliados de outras formas na conversa com a participante de pesquisa.

\section{Gostar e/ou ter que estudar línguas: um processo de significação}

Fabíola começa a entrevista dizendo que adora estudar inglês, demonstrando interesse e entusiasmo pela língua inglesa. Ela iniciou seus estudos ainda no ensino fundamental em um centro de idiomas público, mas, por motivos diversos, teve que interromper o curso. Agora, já no segundo ano do ensino médio, teve outra oportunidade de retomar o curso expresso de LI (curso de três anos), mas novamente não pôde, pois começou a trabalhar durante o dia e estudar à noite.

Em outros momentos da nossa conversa, não sobre EAL (doravante ensino e aprendizagem de línguas), mas sobre suas atividades e hobbies, ela afirmou tentar escrever músicas em inglês. Seu procedimento de criação musical passa pela inspiração em LM e tradução para a LI. Ela inclusive já pediu ajuda, na revisão e tradução das músicas, a uma vizinha que concluiu o curso de graduação em Letras-Tradução na Universidade de Brasília. Fabíola é uma entusiasta da LI. No entanto, quando o foco da conversa muda para a LE, a aluna diz:

Pesq.: Por que você não gosta de espanhol?

Part.: Porque as pessoas falam, eu entendo. Tem algumas coisas que é muito diferente, muito diferente. Às vezes, pra gente significa uma 
coisa e pro outro é uma coisa ruim. Eu entendo e é uma língua que eu consigo pronunciar, é muito fácil. E muito acento, muita coisa chata. Inglês é tão simples. Inglês é tão simples. Eu adoro inglês, sou apaixonada por inglês, escuto música em inglês, procuro a tradução. Faço tudo o que eu puder com o inglês. Nossa, muito fácil, muito, muito fácil. Francês também gosto, gostei, (...)

A estudante não esconde sua falta de empatia pela LE. Primeiramente, justifica seu pouco interesse pela "facilidade" aparente que a língua proporciona aos falantes do português, assertiva que se encaixa no conceito de CEAL de espanhol. No primeiro momento, a LE não parece ser uma tarefa desafiadora para ela, pois, além de tudo, garante conseguir pronunciar a língua. Contudo, ao mesmo tempo em que ela assegura ser fácil, considera que há "grandes" diferenças em relação à LM, indício da contradição da crença maior que é: "espanhol é uma língua fácil" (BARCELOS E KALAJA, 2003 apud BARCELOS \& VIEIRA-ABRAHÃO, 2006, p.18). Fabíola avalia outros aspectos normativos da língua (ex.: acentuação, ortografia) como sendo "chatos", características que se contrapõe a noção de LI como língua "simples", adjetivo repetido duas vezes. Isso nos leva a inferir que o simples se opõe ao complicado, ou seja, ao que não é fácil e, talvez, chato de se estudar ou aprender. Para reforçar seu interesse pela LI, Fabíola assegura fazer tudo o que puder com o inglês e diz ser muito "fácil". Ela relata que seu contato com a LI se dá de maneira frequente, pois se depara com produtos de consumo diversos, expressões em equipamentos e na internet e sempre que vê a LI tem reação diversa de quando encara a LE

Pesq.: Mas você falou que saber ler... Que consegue ler os textos em espanhol? O que falta?

Part.: Eu não tenho curiosidade. Eu gosto de inglês porque eu tenho realmente uma curiosidade de aprender tudo em inglês porque é uma língua muito bonita, mas espanhol, não, não.

A LI é definida também por critério de "beleza", que novamente marca as fronteiras entre LI e LE. Com o desenvolvimento da conversa, é possível perceber que as conotações feitas anteriormente à LE, como: chato (em oposição ao simples), feia (em oposição à LI bonita), são mais bem explicadas por esta última dicotomia pautada na utilidade das línguas

Pesq.: Mas porque você acha que não gosta de espanhol? 
Part.: Não gosto... Porque eu não vejo utilidade nenhuma... Quando uma pessoa tá falado, você vai ter noção do que ela tá falando. Inglês não... Você vai estar boiando. Isso é interessante. Você estar em um grupo do qual você fala a mesma língua e você estar entendendo, entende. Espanhol é muito simples. Você estudar e falar. Agora, você estudar é complicado.

Nota-se que o desafio e a recompensa de se aprender outra língua estão em ter acesso a oportunidades que a LM não oferece. Assim, a LI representa a chave que permite ingressar em lugares demarcados pelo sistema de fronteiras linguísticas. Logo, saber ou não uma língua estrangeira representa sim um sistema de inclusão e exclusão. Contudo, para a nossa participante de pesquisa, a crença de que "espanhol é uma língua fácil” é sustentáculo de seu processo de fixação de identidade de aprendiz de línguas, pois considera não ser necessário estudar para se ter acesso às esferas relativas à LE.

Com os recortes apresentados, é possível perceber que estudar-aprender LI ou LE é um processo identificação e diferenciação, que atravessam os campos do prazer, da beleza, da facilidade-complexidade e da utilidade na vida de Fabíola. A tentativa de fixação de uma identidade ligada a LI é feita sempre num processo de significação que marca diferenças e expõe hierarquias.

Ao relatar sua experiência de ensino nas aulas de LE, é possível notar, na fala de Fabíola, quanto os aspectos motivacionais e afetivos também contribuem para a sua forma de conceber a língua e o processo de ensino:

Pesq.: Mas você só teve aula de espanhol na escola pública, né? Como é que são as aulas lá?

Part.: A minha professora era uma derrota porque ela... A gente falava em sala de aula que ela fez um curso por correspondência. E foi. Correspondência: aprenda espanhol, há! Tático, e a escola precisando de professor, foi lá e contratou. Ela era uma chata (...)

Part.: Ela passava: faça o exercício de tal livro, traduza tal texto, fala tal trava-língua (...). Só isso... E fazer os exercícios do livro que, tipo, eu não sabia nada do que tava naquele livro, nada... falar o objeto nada. Porque eu não gosto de espanhol.

Além do relacionamento interpessoal, pode-se inferir que há dissonâncias entre a abordagem de ensinar e a abordagem de aprender presentes em sala de aula. $\mathrm{Na}$ passagem acima, Fabíola não afirma mais ser tão fácil a LE: "eu não sabia nada do que tava naquele livro", mas justifica sua não-aprendizagem, sobretudo, no fato de não gostar da língua. 
Ao buscarmos saber mais sobre as experiências de ensino-aprendizagem na LE, encontramos percepções negativas sobre os processos de EAL-E (ensino-aprendizagem de língua espanhola) e constatamos que há uma tendência a associar o processo de EAL-E com a primeira professora de língua espanhola, que Fabíola teve no ano anterior. Sobre a atual professora, a aprendiz percebe mudanças nos procedimentos de ensino

Part.: Tá. A desse ano não, ela já é mais calma, ela passa o exercício do livro, ela explica, faz o exercício com a gente porque a gente não tá acostumado, nunca fez espanhol. Mas a outra não, ela era chata e ela não falava direito. É muito chato, muito.

Voltamos nossas perguntas para as questões da LI e os procedimentos em sala de aulas do ensino fundamental e do ensino médio. A fala de Fabíola, em geral, se mostra bastante positiva quanto a materialização das abordagens dos professores que ensinavam LI:

Pesq.: E as aulas? Como eram as aulas de inglês na escola pública, não no CIL (...)

Part.: $\mathrm{Na}$ escola pública foi bom porque eles começam sempre ensinando o simples. Verbo to be, sempre. E é bom, eu fui aprendendo os números e eu fiquei curiosa pra saber os outros, é muito fácil de falar. E o alfabeto então, porque a gente aprendia cantando... One little, two little indians (...)

Pesq.: E como eram as aulas de inglês do professor de inglês?

Part.: Sempre boas. Trabalhos de você passar cartazes traduzindo os alimentos, saladas de frutas fazendo em sala, com os nomes dos alimentos em inglês; números, alfabeto, é o simples... Número, alfabeto, verbo to be, plural, masculino, feminino... Essas coisas. Só o simples mesmo porque o resto a gente só aprende no CIL.

Esta investigação não contemplou a observação direta em sala de aula; contudo, pela entrevista, podemos perceber que tanto as aulas de espanhol como as de inglês abordavam a tradução como método e a progressão dos conteúdos no ensino. Observamos que as experiências de aprendizagem das línguas foram marcadas e significadas de maneiras diversas, positiva e negativamente, e que mesmo se identificando com a LI, para Fabíola a sala de aula de ensino regular ainda não é o espaço para se aprender inglês ou mesmo espanhol. 
Segundo os motivos elencados por Fabíola, aprender línguas se configura como a possibilidade de se transpassar uma porta para novos espaços. Ao perguntarmos o que é língua, Fabíola relata as possibilidades de acesso que a língua dá aos seus falantes:

Pesq.: Língua. O que é língua pra você?

Part.: Bom, no meu caso eu falaria de inglês, que são os benefícios que isso ia me trazer que é, no caso: praticidade e prazer. É inglês é tudo pra mim. (...) É também ia ser muito legal porque, um dia desses, eu fui no CIL porque eu tenho um amigo que tá no terceiro ano do ensino médio. É o Olavo. Ele se formou em inglês no CIL, em espanhol (...). Tá terminando espanhol. E fez francês, só que ai já é particular porque três línguas no CIL já não dá. Então, faltam alguns meses pra ele terminar espanhol no CIL. Francês, falta um ano pra ele terminar. Aí tava lá no CIL, o pessoal da Embaixada foi pra lá. Um bocado de gente nova, sabe, assim... começou a conversar. E ele conversava, assim com muita facilidade, entende. Eu acho isso legal! Conhecer uma cultura nova, pessoas novas, se comunicar com pessoas do outro lado da internet, porque tem coisas na internet que é... Inglês. Porque a internet é... Digamos que você entra num site ou mesmo no Excel algumas coisas são em inglês e que você não vai entender de jeito nenhum, então, você precisa entender. Isso é bom. E por que... pra saber me comunicar, digamos se você for pra outro lugar, eu não vou morrer de fome se eu souber falar. Não, a gente tem que aprender (inglês). Facilita muita coisa. Emprego...

As línguas são associadas às experiências (negativas ou positivas), a CEAL e abordagens específicas, que contribuem para uma concepção sobre línguas e sobre as identidades do aprendiz. Assim, quando falamos em língua como possibilidade de acesso, não falamos de qualquer língua:

Pesq.: E por que você acha que com o espanhol, você não teria todas essas oportunidades?

Part.: Não, porque eu não gosto... E porque é fácil entender o que uma pessoa tá falando em espanhol. É fácil de falar espanhol. Vou saber ler, não como uma pessoa profissional, mas vou saber ler e entender do que se trata o texto. Eu fiz uma prova do Alub escolhi inglês, li francês, li o espanhol... (espanhol) porque é mais prático de você entender eu não gosto, eu não gosto. Os verbos te confundem muito, muito, muito, muito.

Compreende-se da fala acima que a língua inglesa tem o poder de conferir status ao sujeito que a domina. Essa visão é amplamente promovida em nossa sociedade, como afirma Rajagopalan (2005) quando destaca o duplo papel que a língua inglesa 
representa na vida dos brasileiros: por um lado, ela está presente nos diversos meios de comunicação da vida urbana cotidiana, e, por outro, ela se apresenta como instrumento de ascensão social.

\section{Considerações Finais}

Neste artigo, refletimos acerca dos dados coletados em pesquisa realizada com uma estudante de língua inglesa e espanhola de uma escola pública de ensino médio do Distrito Federal. Os dados evidenciaram a pertinência em se considerar identidade e crenças nas questões referentes ao processo de ensino-aprendizagem de línguas estrangeiras, ponderando como esses dois construtos podem estar relacionados entre si e com línguas, que ora nos empenhamos em nos aproximar e dominar ora enfrentamos o desafio de ter que aprender ou aceitá-la impositivamente. Gostando ou não, desejando ou não, aprender uma língua depende de muitos outros fatores e não apenas de um sujeito autoconhecedor, racional e que, pelo esforço, pode tudo. Assim como a constituição das identidades fragmentas e múltiplas, aprender uma língua significa passar por processos de rupturas e permanências linguísticas no contexto da escola pública. Dentro ou fora de sala de aula, e também na interação com outros falantes de línguas, é que os alunos vão se reconhecendo ou desconhecendo com aprendizes, num movimento de comparação contínua.

Apesar da necessidade de se construir como aprendente de língua inglesa, o prazer e a vontade não são garantidores do sucesso na aquisição. A distância que separa o gostar e o aprender LI é tão grande quanto a que divide o não-gostar e ter que aprender LE. A estudante, que sutura temporariamente sua identidade ao desejo de aprender LI e aos discursos que a promovem como língua de prestígio e chave para a ascensão social, necessita encontrar novos espaços e formas para a efetivação da aprendizagem, uma vez que a escola não é vista como promotora de seus anseios. Fabíola atribui papéis e responsabilidades diversas, aos professores e a si mesma, a depender de sua motivação e interesse pelas línguas. Em relação à LI, Fabíola se coloca como sujeito autônomo, esforçando-se em desenvolver estratégias de aprendizagem que contribuam para a aquisição; entretanto, como estudante de espanhol, posiciona-se passivamente no processo, esperado mais do ensino e questionando-o criticamente. Contudo, o que pretendemos salientar aqui, não é apenas o desenvolvimento de uma 
disposição maior ou autonomia perante uma língua específica. Chama-nos mais a atenção a luta pela cristalização de uma identidade ligada a LI, que se dá de forma parecida com o embate pela própria sobrevivência, como sujeito que necessita de outros alimentos que o sustentem no mundo, além da comida. A língua inglesa é o alento para a alma de Fabíola, é a possibilidade de almejar outros caminhos.

Ensinar línguas na escola regular continua sendo desafiador não só pelos obstáculos enfrentados (carga horária exígua, sala superlotadas, falta ou baixa qualidade do material didático, sobrecarga de trabalho, formação dos professores), mas, apesar disso, o ensino e a aprendizagem de línguas ainda operam com os sonhos de alunos dessas aulas tão desacreditadas.

\section{Referências}

ALMEIDA FILHO, J. C. P. Dimensões comunicativas no ensino de línguas. Campinas: Pontes, 2002.

ASSIS-PATERSON, A. A. de, COX, M. I P., SANTOS, D. A. G. dos. Crenças \& Discursos: aproximações. In: Kleber Aparecido da SILVA. (Org.). Crenças, Discursos \& Linguagem. 1 ed. Campinas: Pontes Editores, 2010, p. 195-226.

AUSTIN, J. L. Quando dizer é fazer: palavras em ação. Trad. De Danilo Marcondes de Souza Filho. Porto Alegre: Artes Médicas, 1990.

BARCELOS, A. M. F. Researching Beliefs about SLA: A critical review. In: KALAJA, P.; BARCELOS, A. M. F. (Orgs.) Beliefs about SLA: New Research Approaches. Dordrecht: Kluwer, 2003, p. 7-33.

Metodologia de Pesquisa das Crenças sobre Aprendizagem de Línguas: Estado da Arte. Revista Brasileira de Lingüística Aplicada, v.1, n. 1, 71-92, 2001.

BENVENISTE, E. Da Subjetividade na linguagem. In: Problemas de Linguística Geral I. Tradução: Maria da Glória Novak e Maria Luiza Neri. Campinas, SP: Pontes e Editora da Unicamp, 1988, p. 284-93.

BRASIL. Lei No 11.161, de 5 de agosto de 2005. Presidência da República Casa Civil Subchefia para Assuntos Jurídicos dispõe sobre o ensino da língua espanhola. Diário Oficial da União, Brasília, DF.

JOÃO. In: Bíblia. Disponível em <http://www.bibliaonline.com.br/>. Acesso em: $21 \mathrm{de}$ setembro de 2011. 
LE PAGE, R. B. Projection, Focursing and Diffusio. York Papers in Linguistics, 1980, p. 974.

LEFFA, V. J. Metodologia do ensino de línguas. In: BOHN, H. I.; VANDRESEN, P. Tópicos em lingüística aplicada: o ensino de línguas estrangeiras. Florianópolis: Ed. da UFSC, 1998, p. 211-236.

MOITA LOPES, L. P. Pesquisa interpretativista em Linguística Aplicada: a linguagem como condição e solução. D.E.L.T.A., v. 10, n. 2, 1994. p. 329-338.

ORRÚ, C. M. dos S. F. Língua Materna e Língua Estrangeira: Reconsiderando as Fronteiras. Anais do $6^{\mathbf{0}}$ Seminário de Pesquisas em Linguística Aplicada (SePLA), Taubaté, 2010. ISSN: 1982-8071. CD-Rom.

OTTONI, P. John Langshaw Austin e a Visão Performativa da Linguagem. In: D.E.L.T.A., v. 18, n. 1, p.117-143, 2002.

PEIRCE, B. N. Social identity, investment, and language learning. TESOL Quaterly, v. 29, n. 1, p. 9-31, 1995.

PIOVEZANI FILHO, C. Políticas da voz no discurso político: efeitos da substância da expressão no horário de propaganda eleitoral gratuita. Soletras, Ano VII, n. 13. São Gonçalo: UERJ, 106 jan./jun.2007.

RAJAGOPALAN, K. A. A geopolítica da Língua Inglesa e seus reflexos no Brasil - por uma política prudente e propositiva. In: LACOSTE, Y; RAJAGOPALAN, K. (Orgs.). A geopolítica do inglês. São Paulo, SP: Parábola Editora, 2005, p. 135-157.

SAUSSURE, F. Curso de linguística geral. São Paulo: Cultrix, 1969.

SILVA, K. A. e ROCHA, C. H. Crenças sobre o ensino e a aprendizagem de línguas na linguística aplicada. In: M. H. V. ABRAHÃO; G. GIL; A. S. RAUBER (orgs.), Anais do I Congresso Latino-Americano sobre Formação de Professores de Línguas. Florianópolis, UFSC, $2007 . \quad$ Disponível em: $<$ http://www.cce.ufsc.br/ clafpl/91_KleberdaSilva_E_ClaudiaRocha.pdf $>$. Acesso em 21 de setembro de 2011.

SILVA, T. T. da. A produção social da identidade e da diferença. In: SILVA, Tomaz Tadeu (org. e trad.). Identidade e diferença: a perspectiva dos estudos culturais. Petrópolis: Vozes, 2000. p. 73-102.

Artigo recebido em: 20.12.2011

Artigo aprovado em: 31.05 .2012 